\title{
Comparative Studies on the Acute Toxicities of Whole Solids and Solids Aqueous Extracts Based on the Inhibition of Bacterial Bioluminescence Production
}

\author{
In Chul Kong ${ }^{\dagger}$ \\ Department of Environmental Engineering, Yeungnam University, Gyeongsan 712-749, Korea
}

\begin{abstract}
The aim of this investigation was to demonstrate a rapid bioluminescence bioassay for comparison of the toxicity of whole solids and the aqueous extracts of various environmental solid samples. With regard to the toxicities, those for the soil extracts were mostly found to be lower than those of whole soils, which may have been caused by un-extracted pollutants or dilution during the extraction process. Solid samples from dam-reservoir sediments and municipal refuses were also tested. The toxicities of the solid extracts (0-34\%; refuses and sediments) were much lower than those of the whole solids (13-91\%). The bioluminescence inhibition test indicated that the harmful effects of the contaminated solids samples were greater than those of the solid extracts.
\end{abstract}

Keywords: Aqueous extract, Bioassay, Bioluminescence, Toxicity, Whole solids

\section{Introduction}

Ecosystems are exposed to complex mixtures of various pollutants, chemical species, metabolites and pollutants in complexes with non chemical stressors [1]. Generally, chemical data alone are not sufficient to evaluate the toxic effects of contaminants or characterize a contaminated environment, as chemical data cannot provide information on the effects of chemical compounds and do not take into consideration the interactions between contaminants, matrices and biota [2]. Also, only a limited number of compounds can be analyzed by chemical analyses. Therefore, chemical tests have to be complemented with biological and toxicological methods to determine the effects of contaminants on ecosystems. One major advantage of biological toxicity tests over chemical analyses is that they can directly assess the potential hazard to a soil ecosystem due to a mixture of contaminants [3].

In recent years, various bacterial bioassays have been developed for the screening of chemicals, effluents, sediments, and solids toxicities. The risk of solid-form contaminants is estimated from test-results for both solids extracts and the solid itself [4], which are mostly based on the measurements of growth inhibition, respiration, survival, metabolism, inhibition of enzymatic activity and viability of bacterial cells [3]. Bacterial luminescence bioassays are an important tool, as they are rapid and simple, with no background effects. Constitutive bioluminescence bacteria have been widely used to measure the toxicities at contaminated sites and of treatment processes [5]. In addition to the naturally occurring marine luminous bacterium, Vibrio fischeri, which is widely used in aquatic toxicity testing, luminescent genetically engineered microorganisms (GEMs) have also been created in recent years [6, 7]. Some of these GEMs emit constitutive luminescence and respond to toxicants in a "lightoff" manner; whereas, others emit inducible luminescence and respond to toxicants in a "light-on" basis [8].

The aim of the present study was to demonstrate a rapid bioluminescence bioassay for comparison of the toxicity of whole solids and their aqueous extracts.

\section{Materials and Methods}

\subsection{Strain and Culture Preparation}

The acute toxicity of the samples was determined using a bioluminescent mutant strain, Escherichia coli DH5 RB1436. This mutant strain releases luminescent light during its growth phase [9]. The strain was stored at $-70^{\circ} \mathrm{C}$ until needed, at which time it was grown overnight in Luria-Bertani ${ }^{\mathrm{ka}}\left(\mathrm{LB}^{\mathrm{ka}}\right)$ medium (tryptone $10 \mathrm{~g}$, yeast extract $5 \mathrm{~g}, \mathrm{NaCl} 5 \mathrm{~g}, 2 \mathrm{~N} \mathrm{NaOH} 0.5 \mathrm{~mL}$, kanamycin $50 \mathrm{mg}$ per liter) at $27^{\circ} \mathrm{C}$, with shaking (130 rpm). The strain was diluted 1:30 into $\mathrm{LB}^{\mathrm{ka}}$ medium and allowed to grow until the optical density at $600 \mathrm{~nm}\left(\mathrm{OD}_{600}\right)$ was approximately 0.6. This culture was appropriately diluted with a minimum salt

Received May 13, 2010 Accepted March 03, 2011

cc This is an Open Access article distributed under the terms of the Creative Commons Attribution Non-Commercial License (http://creativecommons. org/licenses/by-nc/3.0/) which permits unrestricted non-commercial use, distribution, and reproduction in any medium, provided the original work is properly cited.
${ }^{\dagger}$ Corresponding Author

E-mail: ickong@ynu.ac.kr

Tel: +82-53-810-2546 Fax: +82-53-810-4624 


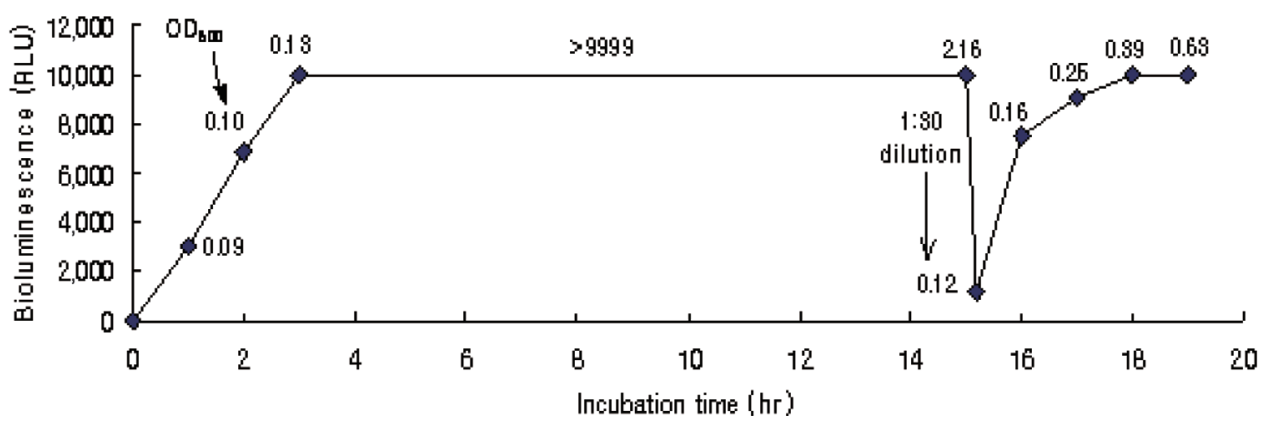

Fig. 1. The time course of the bioluminescent activities of the first and subsequently diluted cultures.

medium $\left(\mathrm{MgSO}_{4} \cdot 7 \mathrm{H}_{2} \mathrm{O} 0.2 \mathrm{~g}, \mathrm{CaCl}_{2} 0.1 \mathrm{~g}, \mathrm{FeSO}_{4} \cdot 7 \mathrm{H}_{2} \mathrm{O} 0.05 \mathrm{mg}\right.$, $\mathrm{NaMoO}_{4} \cdot 2 \mathrm{H}_{2} \mathrm{O} 0.05 \mathrm{mg}, \mathrm{K}_{2} \mathrm{HPO}_{4} 0.43 \mathrm{~g}$, and $\mathrm{KH}_{2} \mathrm{PO}_{4} 0.23 \mathrm{~g}$ ), with a final density for the toxicity test of $\mathrm{OD}_{600}=0.2$.

\subsection{Solids Toxicity Test}

For the development of the solids bioluminescence toxicity test method, soil samples, ranging from 0.1 to $2.0 \mathrm{~g}$, were mixed with a solution of the cultured strain (total working volume 5 $\mathrm{mL}$ ) to determine the optimum ratio of soil to culture, which was continuously incubated for the bioluminescence measurement. The bioluminescence intensities of the experimental sets, containing combusted solids ( $1 \mathrm{~g}$ at $550^{\circ} \mathrm{C}$ for $30 \mathrm{~min}$ ) or $0.5 \mathrm{M}(\mathrm{pH}$ 7.4) phosphate-buffer ( $1 \mathrm{~mL})$ and cultured solution, were compared to determine the conditions for the control set. During the exposure period, the bioluminescence intensity was measured using a Turner 20/20 Luminometer (Turner Designs, Sunnyvale, CA, USA), which has a maximum detection limit of 9,999 relative light units (RLU).

\subsection{Sample Preparation}

Composite solid samples were collected from three different environments: a soil monitoring site, dam-reservoir sediments, and a municipal solid waste (MSW) landfill in Korea. Five samples from each sampling site were collected, with a mixture used as a test solid sample. In the laboratory, the solid samples were dried at ambient temperature $\left(22-25^{\circ} \mathrm{C}\right)$, crushed in a porcelain mortar and sieved through a $2-\mathrm{mm}$ screen. The air-dried samples were stored in cloth bags prior to their subsequent analyses. The bioluminescence inhibitions induced by the different solid samples (high inhibition corresponds to high toxicity) were measured from the test-results for both whole solids and their aqueous-extracts. For the whole solid sample tests, $1 \mathrm{~g}$ of the solid samples was mixed with $4 \mathrm{~mL}$ of the test strain. Solid aqueous extracts were collected using tubes containing $1 \mathrm{~g}$ of solid and $4 \mathrm{~mL}$ p-buffer, after shaking for $60 \mathrm{~min}$ with a bench top wrist-action shaker (Glas-Col, Terre Haute, IN, USA) followed by centrifugation $(4,000 \mathrm{rpm}$ for $20 \mathrm{~min})$. To evaluate the toxicity of the solid aqueous extracts, the supernatant $(2 \mathrm{~mL})$ was mixed with $3 \mathrm{~mL}$ of the bioluminescence strain. The toxicity was determined by measuring the bioluminescence of test samples and a control, with the latter assigned $0 \%$ toxicity.

\section{Results and Discussion}

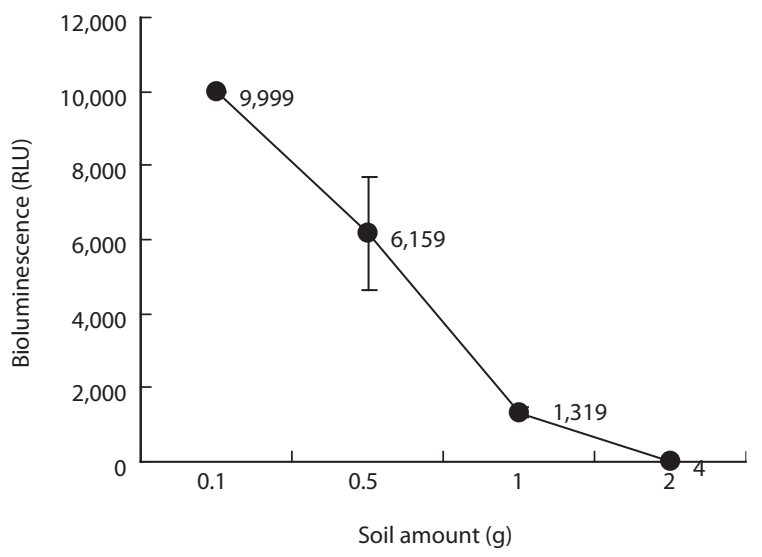

Fig. 2. Effects of soil quantity on the bioluminescence activity of RB1436 in the soil toxicity test.

\subsection{Bioluminescence Characteristics}

To analyze the time course of the bioluminescence activity, the constitutive bioluminescence activity was assayed over a period of several hours (Fig. 1). The maximum (>9,999 RLU) bioluminescence activity typically appeared after $2.5-3 \mathrm{hr}$ of incubation and lasted for approximately $10 \mathrm{hr}$, but this was dependent on the cell conditions and available nutrients. A subsequently diluted subculture (1:30 dilution at $\left.\mathrm{OD}_{600}=2.16\right)$ also showed high bioluminescence activity; 7,519 and 9,052 RLU after 1 and $2 \mathrm{hr}$ of incubation, respectively. This result indicated that the test strain had very useful bioassay characteristics in terms of high and long lasting bioluminescence activity.

\subsection{Conditions for the Solids Toxicity Test}

Soil samples, ranging from 0.1-2.0 g, were mixed with a solution of the cultured strain (total working volume $5 \mathrm{~mL}$ ) to determine the optimum ratio of solid to culture strain. As shown in Fig. 2, the set with $0.1 \mathrm{~g}$ of soil produced over the maximum measurable bioluminescence intensity ( $>9,999$ RLU), indicating no bioluminescence inhibition with this amount of soil. However, complete bioluminescence inhibition ( $4.0 \pm 3.6 \mathrm{RLU})$ was observed in the experiments with $2 \mathrm{~g}$ of soil. This investigation suggested that an amount of solid within the range 0.5-1 g $(6,159 \pm 1,539.3$ to $1,319 \pm 126.9 \mathrm{RLU})$ should be reasonable for 
the toxicity test. In this test, $1 \mathrm{~g}$ of solid (cell to toxicant ratio 4:1) was adopted for further investigation. However, the amount of the extract could be adjusted according to the experimental conditions, such as the type of solids, the degree of pollution and so on. In aqueous toxicity testing, previous investigations have indicated that bioassays can be conducted with cells and sample solutions, with ratios ranging from 1:1 to $1: 9[10,11]$. Generally, a low cell to sample ratio is considered advantageous. A low amount of cells would provide less total surface area for contaminants to be adsorbed, as well as a low dilution effect [6].

To determine the control conditions, the strain $(4 \mathrm{~mL})$ was mixed with combusted $(1.0 \mathrm{~g})$ soil or p-buffer $(1.0 \mathrm{~mL})$ solution, with the results also compared with soil samples. A total of 10 samples were tested. As shown in Table 1, the sets mixed with combusted solids (volatile organic removed) showed an average of $90.4 \pm 8.65 \%(77.7-99.3 \%)$ the bioluminescence intensity of sets with p-buffer; showing similar activities. Therefore, both conditions were able to be adopted as the control, but p-buffer was chosen for this experiment due to its convenience in the bioassay. Prior to this investigation, the bioluminescence activities of the strain with different solutions (distilled water, $0.85 \%$ $\mathrm{NaCl}$, and p-buffer) were also tested to determine the appropriate control solution. Generally, the order of bioluminescence was as follows: $0.85 \% \mathrm{NaCl}>\mathrm{p}$-buffer $>$ distilled water (data not shown). High stimulation ( $>9,999 \mathrm{RLU})$ occurred with $\mathrm{NaCl}$ solution, but only slight inhibition with distilled water. The bioluminescence intensity had to be lower than the maximum value (9,999 RLU); therefore, p-buffer was chosen for the control.

\subsection{Comparative Toxicity of the Whole Soils and Soil Extracts}

Soils consist of a heterogeneous insoluble state of inorganic and organic compounds, as well as a variety of soluble substances [12]. The toxicities of the whole soil and soil aqueous-extracts were obtained and compared (total 15 soil samples). All tests on the extracted samples, as expected, indicated less toxic effects than those using whole soils. The toxicity of a soil aqueous extract may be more related to the bioavailability or the affinity of the contaminants in water environments, such as groundwater and reservoirs, etc. The toxicity measurement of a solid has several advantages over that of a solid aqueous-extract, such as minimization of the dilution of extractable contaminants, direct contact of the test bacteria with the solid matrix, and a more simple procedure [13]. Leitgib et al [2]. reported that direct contact environmental bioassays are able to meet the requirements of environmental toxicology: reliability, sensitivity, reproducibility, rapidity, and low cost.

The total average toxicities of the whole soil and the soil extract were 34.7 and $19.7 \%$, respectively (Table 2 ). With regard to the toxicities, those of the soil extracts were mostly found to be lower than those of whole soils, which may have been caused by un-extracted pollutants or dilution during the extraction process. However, no noticeable correlation $\left(\mathrm{R}^{2}=0.0686\right)$ was observed between the toxicities of the whole soil and soil extract. Such results may be related to the different binding abilities of pollutants to the soil surface, as well as the characteristics of the

Table 1. Comparison of the bioluminescent activities of strain RB1436 mixed with p-buffer and combusted soils for the control conditions

\begin{tabular}{|c|c|c|c|c|c|c|c|}
\hline \multirow{2}{*}{ No. } & \multicolumn{2}{|c|}{ Bioluminescence (RLU) } & \multirow{2}{*}{ Ratio $\left(\mathrm{C} / \mathrm{p} \%{ }^{\mathrm{a}}\right)$} & \multirow{2}{*}{ No. } & \multicolumn{2}{|c|}{ Bioluminescence (RLU) } & \multirow{2}{*}{ Ratio $\left(\mathrm{C} / \mathrm{p} \%^{\mathrm{a}}\right)$} \\
\hline & p-buffer added & Combusted soil & & & p-buffer added & Combusted soil & \\
\hline 1 & 5,373 & 5,285 & 98.4 & 6 & 3,030 & 2,373 & 78.3 \\
\hline 2 & 5,373 & 5,041 & 93.8 & 7 & 3,030 & 3,002 & 99.1 \\
\hline 3 & 5,373 & 5,234 & 97.4 & 8 & 5,130 & 4,916 & 95.8 \\
\hline 4 & 3,030 & 2,354 & 77.7 & 9 & 5,130 & 4,570 & 89.1 \\
\hline 5 & 3,030 & 2,414 & 79.7 & 10 & 5,130 & 4,870 & 94.9 \\
\hline
\end{tabular}

Values are the averages of triplicate experiments.

${ }^{\mathrm{a}} \mathrm{C} / \mathrm{p}$ is the percentage ratio of the combusted soil set to the $\mathrm{p}$-buffer added set.

Table 2. Comparative toxicities of the whole soils and soil extracts

\begin{tabular}{|c|c|c|c|c|c|}
\hline \multirow{2}{*}{ No. } & \multicolumn{2}{|c|}{ Toxicity (\%) } & \multirow{2}{*}{ No. } & \multicolumn{2}{|c|}{ Toxicity (\%) } \\
\hline & Whole soil & Soil extract & & Whole soil & Soil extract \\
\hline 1 & $28 \pm 1.0$ & $27 \pm 10.9$ & 9 & $25 \pm 2.2$ & $19 \pm 2.9$ \\
\hline 2 & $40 \pm 5.1$ & $14 \pm 5.4$ & 10 & $49 \pm 6.7$ & $28 \pm 3.4$ \\
\hline 3 & $27 \pm 6.2$ & $26 \pm 7.2$ & 11 & $32 \pm 3.8$ & $27 \pm 3.7$ \\
\hline 4 & $12 \pm 2.9$ & $11 \pm 7.0$ & 12 & $45 \pm 2.7$ & $22 \pm 5.6$ \\
\hline 5 & $54 \pm 0.5$ & $15 \pm 6.4$ & 13 & $26 \pm 1.9$ & $16 \pm 3.1$ \\
\hline 6 & $33 \pm 6.9$ & $16 \pm 4.9$ & 14 & $26 \pm 10.6$ & $8 \pm 16.2$ \\
\hline 7 & $59 \pm 1.1$ & $35 \pm 7.0$ & 15 & $36 \pm 5.1$ & $18 \pm 1.6$ \\
\hline 8 & $28 \pm 4.8$ & $13 \pm 4.0$ & avg. & 34.7 & 19.7 \\
\hline
\end{tabular}


soil (particle size, composition, organic contents, etc.), resulting in different extractabilities of pollutants in the environment. These differences may vary according to the soil characteristics, such as $\mathrm{pH}$, organic contents, redox potential and other properties of the contaminants. Some studies have shown little correlation between the total heavy metal content and sediment toxicity [14]. Toxicity testing of solids extracts is also important, as dissolved forms of pollutants are more bioavailable in environmental systems, especially groundwater systems [15]. Therefore, a combination of both bioassays could give more valuable information for toxicity assessments. In addition, the results of solids extracts bioassays could show the risk of contaminants to groundwater due to the leaching process of soil contaminants. The main advantage of direct contact is that an interaction occurs between the soil and test organisms; therefore, the mobility and bioavailability of the contaminant is included in the result.

\subsection{Comparative Toxicity of the Whole and Aqueous Ex- tracts of Dam-reservoir Sediments and Landfill Refuses}

In this research, in addition to the soils from the soil monitoring sites in Korea, the toxicities of two different solid matrices were tested: sediments from a dam-reservoir and refuse from a MSW landfill. Both the whole solids and the soil extracts were tested. The refuse and sediments almost completely inhibited the bioluminescence activities (low bioluminescence activity corresponds to high toxicity), showing toxicities in the range of $99.1-100 \%$, with the exception of refuse decomposed for 230 days under controlled conditions $\left(40^{\circ} \mathrm{C}\right.$, moisture contents $>60 \%$ ) (Table 3 ). With respect to the results obtained; however, the direct solid toxicities of the dam-reservoir sediments and refuse were more harmful (more toxic) than those of soil samples from the soil monitoring sites in Korea. Unfortunately, chemical information on the pollutants from each site was unavailable in this investigation. Complementing chemical analyses with environmental toxicity testing is recommended for characterizing the risks of contaminated soil. Although solid toxicity was not found to be related to the general nature (soil, refuse, and sediment) of the solid sample, the solid matrices toxicities were in the following orders: refuse > sediments $>>>>$ soils. Sediments from the dam-reservoir and landfill refuse can be the final collection points for a wide range of chemicals. The average organic contents of solid samples were as follows: soils (3.8\%), sediments $(6.9 \%)$, and refuse (69.8\%). The organic content might be one of the factors effecting toxicity.

Any trend between the two bioassays can not be assessed

Table 3. Toxicities of the whole solids and solids aqueous extracts collected from the dam-reservoir and landfill sites

\begin{tabular}{llcc}
\hline \multirow{2}{*}{ Sites description } & \multicolumn{2}{c}{ Toxicity (\%) } \\
\cline { 3 - 4 } & & Whole solids & Solids extracts \\
\hline \multirow{2}{*}{ Dam-reservoir } & Upper site & $99.9 \pm 0.02$ & $40 \pm 1.5$ \\
& Lower site $^{*}$ Landfill & $99.1 \pm 0.10$ & $18 \pm 5.2$ \\
& Initial $^{\mathrm{a}}$ & $100 \pm 0.00$ & $87 \pm 0.8$ \\
& Biodeg $_{230}{ }^{\mathrm{b}}$ & $65.9 \pm 2.57$ & $9 \pm 2.3$ \\
\hline
\end{tabular}

${ }^{a}$ Initially collected MSW samples.

${ }^{\mathrm{b}}$ Incubated for 230 days at $40^{\circ} \mathrm{C}$ with $60 \%$ moisture $\left(59 \% \mathrm{CH}_{4}\right)$. at present. However; in general, wide differences appeared between the whole solid and aqueous extract toxicities of the sediment and landfill samples. The whole sediments nearly completely inhibited the bioluminescence (high toxicity), but the toxicities of the extracts varied, ranging from 18 to $40 \%$. The refuse whole solid toxicity decreased according to the degree of biodegradation, from 100 to $65.9 \%$, after 230 days of incubation in a vial system; those of the refuse extracts also decreased from 87 to $9 \%$. These reductions were related to complex factors, such as the amount of contaminants, different binding capacities of the pollutants to solids, the type of contaminants and the variable toxic effects of pollutants on the bioluminescence activity [2]. This result also suggests variable bioavailability of pollutants in solid and aqueous environments.

Previous studies have shown that different species and test procedures have their own sensitivity patterns toward toxicants [16]. It is generally believed that a battery of assays, rather than a single assay, would give a better assessment of the toxicity. A test battery could include organisms of different trophic levels, such as a luminescent bacterium, crustacean, alga and fish, for assessing the toxic effects within a wastewater environment [6, 17]. Also, a better bioassessment could be made using a combination of both bioassays, tested with the whole solids and solids extracts.

\section{Conclusions}

In this study, the toxicities for aqueous extracts of solids were mostly found to be lower than those of whole solids, which may have been caused by un-extracted pollutants or dilution during the extraction process. However, no noticeable correlation was observed between the toxicities of the whole solid and solid extract. Although the toxicity of the solids was not found to be related to the general nature (soil, refuse, and sediment) of the solid sample, the order of solid matrices toxicities was refuse, sediments, soils. In addition to the contaminants in each sample, such results may be related to the different binding abilities of pollutants to the solid surfaces, as well as the characteristics of the solid (particle size, composition, organic contents, etc.), resulting in different extractabilities of pollutants in the environment. A combination of assays, using both whole solids and solids extracts, rather than a single assay, could give more valuable information for toxicity assessments of contaminated solid environments.

\section{Acknowledgements}

This research was supported by the Basic Science Research Program, through the National Research Foundation of Korea (NRF), funded by the Ministry of Education, Science and Technology (No. 2010-0022750).

\section{References}

1. Eggen RI, Behra R, Burkhardt-Holm P, Escher BI, Schweigert N. Challenges in ecotoxicology. Environ. Sci. Technol. 2004;38:58A-64A.

2. Leitgib L, Kálmán J, Gruiz K. Comparison of bioassays by testing whole soil and their water extract from contaminated 
sites. Chemosphere 2007;66:428-434.

3. Ahtiainen J, Valo R, Järvinen M, Joutti A. Microbial toxicity tests and chemical analysis as monitoring parameters at composting of creosote-contaminated soil. Ecotoxicol. Environ. Saf. 2002;53:323-329.

4. Robidoux PY, Gong P, Sarrazin M, et al. Toxicity assessment of contaminated soils from an antitank firing range. Ecotoxicol. Environ. Saf. 2004;58:300-313.

5. Choi SH, Gu MB. Toxicity biomonitoring of degradation byproducts using freeze-dried recombinant bioluminescent bacteria. Anal. Chim. Acta 2003;481:229-238.

6. Ren S, Frymier PD. Toxicity of metals and organic chemicals evaluated with bioluminescence assays. Chemosphere 2005;58:543-550.

7. Eldridge ML, Sanseverino J, Layton AC, Easter JP, Schultz TW, Sayler GS. Saccharomyces cerevisiae BLYAS, a new bioluminescent bioreporter for detection of androgenic compounds. Appl. Environ. Microbiol. 2007;73:6012-6018.

8. Gu MB, Gil GC. A multi-channel continuous toxicity monitoring system using recombinant bioluminescent bacteria for classification of toxicity. Biosens. Bioelectron. 2001;16:661-666.

9. Kong IC, Kim M, Bhandari A. Aqueous phase toxicity changes resulting from horseradish peroxidase-mediated polymerization of phenols and hydroxylated polynuclear aromatic contaminants. Bull. Environ. Contam. Toxicol. 2007;79:104108.
10. Scheers EM, Van der Wielen C, Dierickx PJ. Toxicological evaluation of waste-water samples to appropriately sensitized cultured fathead minnow cells compared with the microtox assay. Bull. Environ. Contam. Toxicol. 2002;68:253260.

11. Lajoie CA, Lin SC, Nguyen H, Kelly CJ. A toxicity testing protocol using a bioluminescent reporter bacterium from activated sludge. J. Microbiol. Methods 2002;50:273-282.

12. Ma LQ, Rao GN. Chemical fractionation of cadmium, copper, nickel, and zinc in contaminated soils. J. Environ. Qual. 1997;26:259-264.

13. Bitton G, Garland E, Kong IC, Morel JL, Koopman B. A direct solid-phase assay specific for heavy metal toxicity. I. Methodology. Soil Sediment Contam. 1996;5:385-394.

14. Dave G. Sediment toxicity in lakes along the River Kolbacksan, central Sweden. Hydrobiologia 1992;235-236:419-433.

15. Campbell M, Bitton G, Koopman B. Toxicity testing of sediment elutriates based on inhibition of alpha-glucosidase biosynthesis in Bacillus licheniformis. Arch. Environ. Contam. Toxicol. 1993;24:469-472.

16. Dutka BJ, Nyholm N, Petersen J. Comparison of several microbiological toxicity screening tests. Water Res. 1983;17:1363-1368.

17. Castillo GC, Vila IC, Neild E. Ecotoxicity assessment of metals and wastewater using multitrophic assays. Environ. Toxicol. 2000;15:370-375. 